\title{
Conhecimento científico entrelaçando prática sociocultural do filó e relações de hospitalidade: um estudo bibliográfico
}

Scientific knowledge interlacing Filós sociocultural practice and hospitality relationships:

\author{
a bibliographic study
}

\section{Marcia Maria Cappellano dos Santos}

\author{
Universidade de Caxias do Sul - UCS - Caxias do Sul - Rio Grande do Sul - Brasil \\ Samara Camilotto
}

Universidade de Caxias do Sul - UCS - Caxias do Sul - Rio Grande do Sul - Brasil

\begin{abstract}
Resumo: O filó, encontro realizado na zona rural à noite, geralmente aos sábados, congregando famílias, amigos e vizinhos, é uma prática sociocultural que faz parte da história da imigração italiana no estado do Rio Grande do Sul. Nele, as pessoas conversavam sobre seus cotidianos, comiam e bebiam o que, através do trabalho na roça, era fornecido pelo solo; exprimiam sua fé na religião através da reza, praticavam jogos, faziam artesanato para decoração das casas e vestimentas, ou então confeccionavam ferramentas para o trabalho no campo, e também cantavam sobre suas dores e sobre suas esperanças. Laços de hospitalidade concretizavam a prática como encontro de comunhão, celebração e trocas. Partindo desse contexto, este artigo tem o objetivo de identificar e descrever estudos que abordam direta ou indiretamente o filó e que o analisam pelo viés da hospitalidade. Assim, esta pesquisa caracteriza-se como bibliográfica, tendo sido realizada em livros, artigos, dissertações, teses e anais de eventos. Os resultados apontam que apenas um estudo tem como foco central o filó, sendo que os demais descrevem a prática no decorrer do trabalho como informação ou resultado adicional às pesquisas realizadas. Outros acessos advieram provavelmente de link com o radical "filo", remetendo, dentre outras, a produções relacionadas a filosofia, filologia, filogenética. Tal lacuna configura-se assim como uma justificativa para o desenvolvimento de pesquisa de mestrado em andamento, da qual a prática sociocultural do filó compõe o objeto de estudo.
\end{abstract}

Palavras-chave: Hospitalidade. Filó. Produção bibliográfica.

Abstract: The Filó, held in the countryside at night, usually on Saturdays, bringing together families, friends and neighbors, is a sociocultural practice that is part of the history of Italian immigration in the state of Rio Grande do Sul. In Filó, people talked about their everyday lives, ate and drank what, through work in the countryside, was supplied by the soil; they expressed their faith in religion through prayer, played games, made handicrafts for house decoration and clothing, or made tools for countryside work, and they also sang about their pains and their hopes. Ties of hospitality made possible the practice as a meeting of communion, celebration and exchanges. From this context, this article aims to identify and describe studies that directly or indirectly address the Filó and analyze it through the hospitality perspective. Thus, this research is characterized as bibliographical, having been carried out in books, articles, dissertations, theses and annals of events. The results point out that only one study has as its central focus the Filó; the others describe the practice during the work as information or additional result to the research carried out. Other accesses probably came from a link with the radical "filo", referring, among others, to productions related to philosophy, philology, phylogenetics. Such a gap is thus a justification for the development of this master's research in progress, from which the sociocultural practice of the Filó composes the object of study.

Keywords: Hospitality. Filó. Bibliographic production. 


\section{Introdução}

O filó é uma prática sociocultural que faz parte da história da imigração italiana no estado do Rio Grande do Sul. A partir de 1875, o processo de migração, em que italianos saíram de seu país em busca de um novo futuro no Brasil, culminou na descoberta de uma terra nova, com condições geográficas diferentes da de origem. Os primeiros italianos, especificamente, "[...] tiveram de se contentar com lotes localizados no planalto, numa região coberta de mata - a encosta da serra." (TRENTO, 1989, p. 85), região atualmente denominada como Serra Gaúcha, tendo em conta que os alemães, que imigraram para o país a partir de 1824, residiam nas regiões planas.

Na Serra Gaúcha, a separação das colônias em lotes contendo aproximadamente 25 hectares fez com que os imigrantes construíssem suas casas próximas às linhas (caminhos estreitos para divisão das terras) (MANFROI, 1975). Dessa forma, os italianos depararam-se com um novo modo de viver intracomunitário, tendo em conta que as residências vizinhas, antes muito próximas, passaram a distanciar-se em cerca de 300 metros.

Por conta dessa distância entre as casas, o filó emergiu como prática de convivência. Conforme Ribeiro (2004, p. 340),

O filó pode ser definido como o costume de reuniões entre parentes ou vizinhos mais próximos. Eram encontros sociais nas cozinhas, ou nas cantinas domésticas, sobretudo na zona rural. Dele participavam homens, mulheres, jovens e crianças. De um modo geral, fazia-se o filó aos sábados à noite, porque, no dia seguinte (domingo), não havia necessidade de levantar cedo para trabalhar. (Grifos da autora).

Por meio desses encontros noturnos, os imigrantes tomavam conhecimento sobre as "[...] notícias da Itália, dos parentes e amigos que permaneceram por lá. Também se trata de um momento em que as cartas recebidas da Itália eram lidas para todos os presentes" (GOMES; LAROQUE, 2010, p. 39).
Partindo dessa contextualização, percebe-se que essa prática oportunizava a agregação e o fortalecimento de vínculos sociais entre os imigrantes italianos e, consequentemente, de relações de hospitalidade. Alguns estudos expõem que esses encontros ainda são realizados pelos descendentes daqueles imigrantes, mesmo que com mudanças em sua finalidade (GOMES, 2008; GOMES; LAROQUE, 2010). Assim, surge a oportunidade de analisar o filó a partir da lente teórica da hospitalidade/acolhimento ${ }^{1}$.

Precedentemente a uma análise aprofundada acerca de relações de hospitalidade em filós, considerou-se relevante conhecer de que forma avança o conhecimento científico sobre esse tema. Assim, este artigo, reportando parte de pesquisa de Mestrado ainda em desenvolvimento, apresenta panoramicamente estudos que abordam filós, direta ou indiretamente, analisando-os pelo viés da hospitalidade.

\section{Metodologia}

Com escopo de identificar e analisar as principais contribuições teóricas existentes sobre esse tema, a pesquisa, conforme a distingue Köche (2002), caracteriza-se como bibliográfica. desenvolvimento do processo investigativo requer, pois, consulta em fontes diversas, abrangendo diferentes gêneros acadêmicos, os quais, neste trabalho, consistiram em teses, dissertações, artigos e anais de eventos - estes, tendo o reconhecimento da comunidade científica da área. Ressalte-se que a consulta limitou-se a fontes bibliográficas nacionais pela natureza do tema investigado.

\subsection{Caminhos da pesquisa}

A pesquisa inicialmente realizada no Banco de Teses e Dissertações da Capes, utilizando o termo de

\footnotetext{
${ }^{1}$ Perazzolo, Ferreira, Santos e Zerger (2016, p. 542) justificam a adoção dos termos "hospitalidade" e "acolhimento" como equivalentes, com a concepção de que hospitalidade e acolhimento são termos que se permeiam e se referem, respectivamente, à forma e à dinâmica do fenômeno que se constitui no espaço "entre" sujeitos em interação, potencializando-lhes o crescimento e a transformação nas perspectivas individual e coletiva.
} 
busca "filó", gerou 20 resultados, porém, com acesso somente a três, sendo que nenhum desses faz referência ao termo no sentido que aqui lhe é conferido. Num segundo momento, incluindo a palavra "italiano", foram encontrados 1611 trabalhos, estando 283 disponíveis para acesso. Desses, o único que aborda a prática sociocultural, objeto deste trabalho, é a tese de Patrícia Pereira Porto intitulada "O cancioneiro popular da imigração italiana: a leitura como processo de construção de sentidos na performance da canção" publicada em 2015 para o Doutorado em Letras da Universidade de Caxias do Sul em associação ampla com a UniRitter. Outros acessos advieram provavelmente de link com o radical "filo", remetendo a produções, dentre outras, relacionadas a filosofia, filologia, filogenética.

Considerado o resultado da pesquisa no Portal de Teses e Dissertações da Capes e numa tentativa de expansão da busca, foi acessado o repositório de teses e dissertações da Universidade de Caxias do Sul. Sem a inclusão do termo "italiano" junto a "filó", obteve-se somente um resultado, o qual estabelece relação com "filo", nível utilizado na classificação científica dos seres vivos. A inclusão do termo levou a 23 resultados, oito reportando à prática sociocultural do filó. Quanto aos demais, repete-se o constatado no Portal de Teses e Dissertações da Capes, relativamente a derivações do link com "filo".

O Quadro 1 elenca os oito trabalhos identificados, neles incluída a tese de Patrícia Pereira Porto, já mencionada.

Quadro 1 - Dissertações e Teses no Repositório da UCS que abordam o filó

\begin{tabular}{|c|c|c|c|}
\hline Autor & Título & $\begin{array}{l}\text { Mestrado ou } \\
\text { Doutorado }\end{array}$ & Ano \\
\hline $\begin{array}{l}\text { TOSCAN, M. } \\
\text { P. }\end{array}$ & $\begin{array}{l}\text { O } \\
\text { Comportamento } \\
\text { Linguístico na } \\
\text { Comunidade } \\
\text { Bilíngue Ítalo- } \\
\text { Brasileira de } \\
\text { Nova Pádua/RS: } \\
\text { Identidade, } \\
\text { Prestígio e } \\
\text { Estigma } \\
\text { Linguísticos }\end{array}$ & $\begin{array}{l}\text { Mestrado em } \\
\text { Letras e } \\
\text { Cultura } \\
\text { Regional }\end{array}$ & 2005 \\
\hline $\begin{array}{l}\text { FILIPPON, } \\
\text { M. I. }\end{array}$ & $\begin{array}{l}\text { A casa do } \\
\text { imigrante italiano, } \\
\text { a linguagem do } \\
\text { espaço de } \\
\text { habitar. }\end{array}$ & $\begin{array}{l}\text { Mestrado em } \\
\text { Letras e } \\
\text { Cultura } \\
\text { Regional }\end{array}$ & 2007 \\
\hline
\end{tabular}

\begin{tabular}{|c|c|c|c|}
\hline $\begin{array}{l}\text { MACIEL, M. } \\
\text { B. }\end{array}$ & $\begin{array}{l}\text { A pátria sem } \\
\text { fronteiras: } \\
\text { imigração italiana } \\
\text { na ficção de } \\
\text { Fidélis Dalcin } \\
\text { Barbosa }\end{array}$ & $\begin{array}{l}\text { Mestrado em } \\
\text { Letras e } \\
\text { Cultura } \\
\text { Regional }\end{array}$ & 2007 \\
\hline $\begin{array}{l}\text { VALDUGA, } \\
\text { V. }\end{array}$ & $\begin{array}{l}\text { O Processo de } \\
\text { Desenvolvimento } \\
\text { do Enoturismo no } \\
\text { Vale dos } \\
\text { Vinhedos }\end{array}$ & $\begin{array}{l}\text { Mestrado em } \\
\text { Turismo }\end{array}$ & 2007 \\
\hline $\begin{array}{l}\text { DA CÁS, L. } \\
\text { E. }\end{array}$ & $\begin{array}{l}\text { Aspecto Lírico- } \\
\text { Religioso das } \\
\text { Canções } \\
\text { Marianas: Um } \\
\text { estudo sobre as } \\
\text { metáforas e } \\
\text { metonímias que } \\
\text { representam } \\
\text { Maria }\end{array}$ & $\begin{array}{l}\text { Mestrado em } \\
\text { Letras, } \\
\text { Cultura e } \\
\text { Regionalidade }\end{array}$ & 2009 \\
\hline $\begin{array}{l}\text { THOEN, C. } \\
\text { F. C. }\end{array}$ & $\begin{array}{l}\text { Representações } \\
\text { sobre Etnicidade } \\
\text { e Cultura Escolar } \\
\text { nas Antigas } \\
\text { Colônias de } \\
\text { Imigração Italiana } \\
\text { do Nordeste do } \\
\text { Rio Grande do } \\
\text { Sul (1905 - 1950) }\end{array}$ & $\begin{array}{l}\text { Mestrado em } \\
\text { Educação }\end{array}$ & 2011 \\
\hline $\begin{array}{l}\text { NARDIN, C. } \\
\text { R. }\end{array}$ & $\begin{array}{l}\text { Gostos, Aromas e } \\
\text { Sabores: } \\
\text { Memórias e } \\
\text { Turismo } \\
\text { Gastronômico em } \\
\text { Bento Gonçalves }\end{array}$ & $\begin{array}{l}\text { Mestrado em } \\
\text { História }\end{array}$ & 2015 \\
\hline $\begin{array}{l}\text { PORTO, P. } \\
\text { P. }\end{array}$ & $\begin{array}{l}\text { O cancioneiro } \\
\text { popular da } \\
\text { imigração italiana: } \\
\text { a leitura como } \\
\text { processo de } \\
\text { construção de } \\
\text { sentidos na } \\
\text { performance da } \\
\text { canção }\end{array}$ & $\begin{array}{l}\text { Doutorado em } \\
\text { Letras } \\
\text { (associação } \\
\text { ampla UCS- } \\
\text { UniRitter) }\end{array}$ & 2015 \\
\hline
\end{tabular}

Fonte: Elaborado pelas autoras (2017).

Quanto aos periódicos, foram acessados aqueles abrigados por Programas de Pós-Graduação nas áreas de Turismo e Hospitalidade e em funcionamento, constantes da Plataforma Sucupira². Compõe o conjunto desses periódicos: Revista Hospitalidade (Universidade Anhembi Morumbi UAM); Revista Cenário - (Universidade de Brasília UNB); Revista de Turismo Contemporâneo (Universidade Federal do Rio Grande do Norte UFRN); Turismo: Visão e Ação (Universidade do Vale do Itajaí - UNIVALI); Turismo em Análise (Universidade de São Paulo - USP); Turismo e Sociedade (Universidade Federal do Paraná UFPR); Rosa dos Ventos - Turismo e Hospitalidade (Universidade de Caxias do Sul - UCS). Além desses, incluiu-se a Revista Brasileira de Pesquisa

2 Portal de buscas sobre pesquisa e programas de pósgraduação no Brasil. 
em Turismo, publicação da Associação Nacional de Pesquisa e Pós-Graduação em Turismo - ANPTUR.

A busca em artigos foi realizada no site dos periódicos em cujo campo de pesquisa "Conteúdo" foi inserido o termo "filó". Diferentemente do procedimento em teses e dissertações, aqui não foi incluída a palavra "italiano", tendo em conta que o sistema de pesquisa dos sites consideraria "filó italiano" como um único termo.

Com a consulta, chegou-se apenas ao artigo "A Viagem e a Memória do Idoso: um estudo na região da Serra Gaúcha", de autoria de Susana de Araújo Gastal, Ana Maria de Paris Possamai e Airton da Silva Negrine, publicado na revista Turismo em Análise, volume 21, número 1, de abril de 2010.

Relativamente aos anais de eventos, a busca se deu em dois eventos reconhecidos como relevantes no panorama da pesquisa em Turismo e Hospitalidade no Brasil: o Seminário Anual da Associação Nacional de Pesquisa e Pós-Graduação em Turismo (ANPTUR) e o Seminário de Pesquisa em Turismo do MERCOSUL - SeminTUR, promovido pelo Programa de Pós-Graduação em Turismo e Hospitalidade, da Universidade de Caxias do Sul.

Como se pode constatar no site das últimas edições dos eventos (XIII SEMINÁRIO ANPTUR, 2016 e 8 EMINTUR, 2016) o Seminário ANPTUR define-se como um fórum de debate, reflexões e propostas de pesquisadores, docentes e estudiosos da área do Turismo, e o SeminTUR, como um espaço em que pesquisadores de instituições brasileiras e estrangeiras, particularmente do Mercosul, socializam o conhecimento produzido sobre Turismo e Hospitalidade, visando contribuir para o amadurecimento dessas áreas.

No Portal da ANPTUR, com exceção da primeira edição do evento, as demais, da segunda, em 2005, até a décima terceira, em 2016, disponibilizam-se os anais, nos quais se encontram 1795 artigos. Para a pesquisa, cada um deles foi acessado com um leitor de arquivo PDF, utilizando o atalho de teclado Ctrl + $\mathrm{f}$ e incluindo o termo "filó".

A busca gerou seis artigos (Quadro 2), sendo que todos foram publicados em edições diferentes.
Quadro 2 - Artigos publicados no Seminário ANPTUR contendo o termo "filó"

\begin{tabular}{|c|c|c|}
\hline $\begin{array}{l}\text { Edição } \\
\text { do } \\
\text { evento }\end{array}$ & Título do artigo & Autor(es) \\
\hline II - 2006 & $\begin{array}{l}\text { O desenvolvimento } \\
\text { econômico de Caxias do Sul } \\
\text { na perspectiva do acervo do } \\
\text { Museu Municipal }\end{array}$ & SALES, F. de L. \\
\hline$V-2008$ & $\begin{array}{l}\text { O Processo de } \\
\text { desenvolvimento do } \\
\text { enoturismo no Vale dos } \\
\text { Vinhedos - RS }\end{array}$ & VALDUGA, V. \\
\hline VI-2009 & $\begin{array}{l}\text { A Viagem e a Memória do } \\
\text { Idoso }\end{array}$ & $\begin{array}{l}\text { POSSAMAI, A. } \\
\text { M. D. P.; } \\
\text { GASTAL, S.; } \\
\text { NEGRINE, A. }\end{array}$ \\
\hline IX -2012 & $\begin{array}{l}\text { Estado e turismo: a } \\
\text { construção do patrimônio do } \\
\text { vinho no RS (Brasil) de } 1900 \\
\text { a } 1930\end{array}$ & VALDUGA, V. \\
\hline $\begin{array}{l}\mathrm{XII-} \\
2015\end{array}$ & $\begin{array}{l}\text { Enoturismo no Vale dos } \\
\text { Vinhedos/RS: uma análise } \\
\text { da oferta e da demanda } \\
\text { turística }\end{array}$ & $\begin{array}{l}\text { VALDUGA, V.; } \\
\text { OLIVEIRA, B. }\end{array}$ \\
\hline $\begin{array}{l}\mathrm{XIII-} \\
2016\end{array}$ & $\begin{array}{l}\text { As relações de hospitalidade } \\
\text { na memória sobre os filós } \\
\text { em uma região de } \\
\text { colonização italiana no Rio } \\
\text { Grande do Sul }\end{array}$ & $\begin{array}{l}\text { CAMILOTTO, } \\
\text { S.; SANTOS, M. } \\
\text { M. C. }\end{array}$ \\
\hline
\end{tabular}

Fonte: Elaborado pelas autoras (2017).

Observa-se que três dos seis artigos têm um mesmo nome em sua autoria, e os autores daquele publicado em 2009 são os mesmos que assinam o artigo de 2010 publicado na revista Turismo em Análise.

O site do Semintur disponibiliza para acesso 912 trabalhos entre artigos e resumos expandidos, publicados em oito edições do evento, dos anos de 2003 a 2015, sendo que somente o artigo "O desenvolvimento econômico de Caxias do Sul na perspectiva do acervo do Museu Municipal", de autoria de Fabiana de Lima Sales, contém, no corpo do texto, o termo "filó". Este, porém, foi publicado na edição de 2006 realizada conjuntamente ao Seminário ANPTUR, estando, por isso, duplicado na pesquisa realizada.

Entre dissertações, teses, anais de eventos e artigos publicados em periódicos, alcançou-se o total de 15 trabalhos, os quais ora serão sinteticamente descritos.

\section{Descrição dos resultados}

A dissertação "A casa do imigrante italiano, a linguagem do espaço de habitar" de Maria Isabel 
Filippon, possui como foco "[...] estudar a transformação do espaço de habitar do imigrante italiano e dos seus descendentes, na Região Colonial Italiana $(\mathrm{RCI})$, através da literatura ficcional que permite fazer o intercâmbio entre a história e a arquitetura." (FILIPPON, 2007, p. 9).

No capítulo "O Espaço de Habitar do Imigrante Italiano", especificamente na página 45 , a autora apresenta a cozinha como um dos espaços mais utilizados, sobretudo para o convívio familiar e exemplifica através da obra de ficção "O Quatrilho", escrita por José Clemente Pozenato:

[...] o narrador apresenta a cena de um filó encontro que se dava no período da noite realizada pelas famílias de determinada comunidade -, ocorrido na casa do personagem Aurélio, em que os vizinhos e amigos se encontram, em torno do "fogolar", instalado na cozinha, para um momento de lazer. "Aurélio apanhou o baralho alto da prateleira. Fazia bem dez anos que não era usado. Ainda cheirava um pouco a querosene que passara nas cartas, à tarde, para tirar o mofo. Abancou-se da mesa com o velho Cósimo, Beppe e o pai de Teresa. - Os mais novos vão jogar cartas - brincou o velho Cósimo. - Os velhos vão esquentar o reumatismo perto do fogo. O que é que se joga? - O quatrilho - propôs Aurélio. Ângelo, Mássimo, mais o Giácomo e o Agostinho, ficaram por ali para apreciar o jogo. As mulheres se acomodaram nos bancos em roda do fogolar". (FILIPPON, 2007, p. 45, grifos da autora).

No capítulo em que aprofunda a obra, Filippon (2007) descreve o filó, o primeiro na casa de Aurélio após a morte da matriarca Rosa: os homens se reúnem para jogar quatrilho e as mulheres se acomodam ao redor do fogolar e conversam sobre crochê, sobre os próximos casamentos da comunidade e sobre a comida e a bebida a serem servidas no encontro (batata-doce, pipoca, quentão e vinho). Ali acontece a primeira troca de olhares entre Teresa e Máximo - ele casado com a prima dela, Pierina. É o início do enredo principal da história.

Na sequência ressalta que a "[...] descrição do filó desvela aspectos tipicamente culturais da $\mathrm{RCl}$ [...]", e, em especial, Filippon (2007, p. 78) expõe que a função da cozinha é mais que somente local de serviço:
A cozinha é um lugar essencial na casa do imigrante, o fogolar exerce um poder aglutinador, as pessoas ficam ao seu redor, cumprindo as suas lidas diárias, bem como nos raros momentos de lazer. É, portanto, um lugar que não cumpre apenas a função de serviço, é também o local de estar, dos encontros sociais.

O encontro ainda é retratado em outros momentos na obra "O Quatrilho", mas como rememoração daquele que ocorre no início da história com o cruzamento da vida dos casais Máximo e Pierina e Ângelo e Teresa.

A pesquisa denominada "Representações sobre Etnicidade e Cultura Escolar nas Antigas Colônias de Imigração Italiana do Nordeste do Rio Grande do Sul (1905-1950)" e realizada por Carla Fernanda Carvalho Thoen buscou, "[...] a partir de documentos orais que integram o Acervo de Memória Oral da UCS, [...] analisar os sentidos conferidos à escolarização através das narrativas dos professores e líderes comunitários entrevistados." (THOEN, 2011, p. 11). A autora apresenta o filó ao relatar os motivos para a vinda dos imigrantes italianos ao Brasil em meados do século XIX. Conforme Thoen (2011, p. 37), na Itália, esses "momentos de encontro das famílias, à noite, que se reuniam para confraternizar", difundiam o mito de América promissora. Ao relatar a vida cotidiana dos imigrantes italianos, quando já no Brasil, Thoen (2011, p. 44) destaca ser o filó

[...] importante agente socializador e propiciava ajuda/apoio mútuo entre as famílias. Nos encontros, que ocorriam à noite, as mulheres costuravam, bordavam, faziam a dressa. Os homens jogavam mora, cartas, conversavam sobre inúmeros assuntos, cantavam, oravam.

$\mathrm{Na}$ dissertação, "O comportamento linguístico na comunidade bilíngue ítalo-brasileira de Nova Pádua/RS: identidade, prestígio e estigma linguístico", ao abordar aspectos socioculturais da Colônia Caxias no final do século XIX, Toscan (2005, p. 36) reportase ao filó como um "encontro entre famílias ou amigos, na casa de um ou de outro, à noite.": 
No início da colonização, a vida em família incluía muita reza, principalmente à noite. As crianças rezavam antes do jantar e após rezava-se o terço. Frequentemente, reuniamse à noite para fazer novenas, que normalmente terminavam em filós. Nesses encontros, conversavam, cantavam, jogavam cartas e mora. As crianças brincavam no sótão ou no pátio e a família anfitriã oferecia petiscos como amendoins, pipocas, etc. e pode-se dizer que um filó era sempre uma alegre festa.

Sobre a $16^{\mathrm{a}}$ Légua da Colônia Caxias, Nova Pádua, a autora destaca que pobreza não era motivo para tristeza, e esses encontros - quase diários até o advento da televisão, conforme um entrevistado afirmou - eram o momento de se divertir e compartilhar a caça e a pesca (TOSCAN, 2005).

A pesquisa de Patrícia Pereira Porto, única tese dentre os resultados da busca, objetiva "[...] compreender o processo de construção de sentido na performance das canções que compõem o acervo do Cancioneiro Popular da Imigração Italiana." (PORTO, 2015, p. 12). O canto, para os imigrantes italianos, tinha a função de agregação social. Dentre os relatos das entrevistas feitas pela autora, o filó aparecia como um espaço para o canto e o próprio deslocamento propiciava momentos para entoar canções: "[...] conta que era habitual pessoas andarem quilômetros para fazer o filó [...] e pelo caminho entoavam canções da imigração italiana." (PORTO, 2015, p. 31).

Apesar de o foco do trabalho ser o canto e as canções, ao referirem-se sobre o filó, os entrevistados também ressaltaram os fazeres e as comidas que caracterizavam esses encontros:

[...] os filós eram uma união de famílias, que levavam batata doce, vinho, quentão, jogavam cartas e cantavam. [...] as palhas para a realização das dressas eram escolhidas a partir do trigo que estaria mais viçoso e que, após a colheita do trigo, se juntavam para cortar a espiga, separar as folhas e organizar as palhas por tamanho; enquanto isso, tomavam chimarrão e cantavam. (PORTO, 2015, p. 104-105).

Com as mudanças decorridas no passar dos tempos, a prática, na ótica de entrevistados pela pesquisadora, possui, atualmente, o formato de festa gastronômica e é aberta à visitação de turistas. Destacam, ainda, que eventualmente apresentam-se formações corais. Observe-se, nas manifestações dos entrevistados, a referência a uma possível prática turística atribuída ao filó, o que lhe confere outra conotação social.

A dissertação "Aspecto Lírico-Religioso das Canções Marianas: Um estudo sobre as metáforas e metonímias que representam Maria" de Lauro Edson Da Cás "[...] objetiva demonstrar a importância da religiosidade para a vida e ou para a recuperação e reordenamento cultural do imigrante italiano na Região de Colonização Italiana." (DA CÁS, 2009, p. 9).

Como o foco do trabalho são três canções marianas, ao abordar o filó, ressalta-se o canto. O autor utiliza a definição de Ribeiro $(2002)^{3}$ e destaca que, com a realização desses encontros, "[...] a distância geográfica e física se encurtava gradualmente.”. Sobre o canto, Da Cás (2009, p. 4142) expõe:

Cantavam a vida e construíam o universo representativo a partir das variantes que 0 grupo acabava tendo. Ressalta-se, também, que os cantos eram executados sem 0 acompanhamento de instrumentos musicais. Isso foi gerando a criação e a formação de grupos de corais, geralmente integrados pelos membros da família. Trocavam canções, pois era uma forma de integração, isto é, poderia ter vizinhos que sabiam de outras canções (um dos motivos, também, pode ser associado ao fato que fora mencionado anteriormente, o aspecto de virem de regiões diversificadas, mas que estavam próximos agora).

"A pátria sem fronteiras: imigração italiana na ficção de Fidélis Dalcin Barbosa", de Marcele Brusa Maciel, tem como propósito analisar aspectos referentes à representação da imigração italiana em duas obras do escritor Fidélis Dalcin Barbosa (MACIEL, 2007).

O filó é apresentado no subcapítulo em que a autora aborda o papel da mulher nas obras

\footnotetext{
3 "Ribeiro (2002, p. 74) descreve o filó como uma reunião convivial entre vizinhos, realizados à noite, frequentemente aos sábados, na qual os participantes jogavam cartas, tomavam vinho, cantavam; as mulheres fiavam ou compartilhavam histórias às crianças." (DA CÁS, 2009, p. 31).
} 
selecionadas para análise. Conforme a autora, existe uma clara divisão de papéis entre homem e mulher, que não é discutida nas obras, mas apresentada como normal para a convivência em família, ou seja, "[...] representa, sob a ótica da narrativa, o comportamento adequado para homens e mulheres na sociedade." (MACIEL, 2007, p. 39).

O lazer, segundo Maciel (2007), era uma prática masculina. Ao apresentar um conto da obra "Semblantes de Pioneiros", a autora explica que, enquanto os homens se divertem, as mulheres são responsáveis pela preparação e andamento da festa. Na sequência, é exposta uma definição de filó por Ribeiro $(2002)^{4}$ e, ao analisá-la, também se observa a divisão de papéis:

Ainda que todos participassem, os homens jogavam, bebiam e cantavam. As mulheres, por sua vez, fiavam e contavam histórias às crianças. Ou seja, o lazer cabia aos homens, pois fiar também é uma forma de trabalho, bem como contar histórias, uma maneira de cuidar das crianças. (MACIEL, 2007, p. 39).

Caroline Rigo Nardin, em sua dissertação intitulada "Gostos, aromas e sabores: memórias e turismo gastronômico em Bento Gonçalves", pesquisa a culinária dos imigrantes italianos, da região de Bento Gonçalves, como instrumento de memória coletiva e sua transformação em turismo gastronômico (NARDIN, 2015).

A autora analisa festas religiosas em Bento Gonçalves e o significado simbólico do alimento nesses eventos. A Festa de Santo Antônio, padroeiro do município, tornou-se "[...] a maior festa popular religiosa [...]" (NARDIN, 2015, p. 47). Em suas primeiras edições, eram realizados filós

[...] nas casas das pessoas da comunidade, um momento de conversa, regado a comidas e o sagrado vinho. A comida, nesse sentido, pode adquirir vários significados, com características particulares, durante celebrações, rituais de celebração particulares (batizados, casamentos...) ou os de importância coletiva. Nessas ocasiões,

\footnotetext{
4 "As festas e os filós (reunião convivial entre vizinhos, realizados à noite, frequentemente aos sábados, na qual os participantes jogavam cartas, tomavam vinho, cantavam; as mulheres fiavam ou contavam histórias às crianças) foram, dentre outas, ocasiões privilegiadas para que essas trocas se efetuassem."
}

consumiam-se alimentos que poucas vezes estavam presentes durante o resto do ano. (NARDIN, 2015, p. 48).

Quatro trabalhos resultantes da pesquisa sobre o filó em artigos, dissertações, teses e anais de eventos têm como autor Vander Valduga, sendo três anais do Seminário da ANPTUR e o outro, sua dissertação para o Mestrado em Turismo da Universidade de Caxias do Sul, no ano de 2007. O foco das pesquisas de Valduga é o enoturismo no Vale dos Vinhedos, região vinícola situada na Serra Gaúcha e que abrange os municípios de Bento Gonçalves, Garibaldi e Monte Belo do Sul.

$\mathrm{Na}$ dissertação "O processo de desenvolvimento do enoturismo no vale dos Vinhedos", Valduga (2007) apresenta pesquisas que, à época, já haviam sido desenvolvidas na região. Dentre essas, a de Soares (2004) que analisa o vinho pela ótica da hospitalidade. No filó, exposto como encontro típico italiano, o vinho se relaciona com a hospitalidade, pois "[...] proporciona a alegria desses encontros e o convívio." (VALDUGA, 2007, p. 68).

Em 2008, para o Seminário da ANPTUR, Valduga discorre sobre alguns dos resultados obtidos em sua pesquisa para o mestrado. O filó é apresentado como forma de expressão da cultura local, e o autor o descreve como "[...] encontros realizados entre as famílias em momentos de alegria ou sofrimento." (VALDUGA, 2008, s/p).

Em outro trabalho publicado nos anais do seminário, no ano de 2012, Valduga objetiva "[...] analisar o papel do Estado na vitivinicultura e sua patrimonialização, apresentando o turismo como vetor desse processo." (VALDUGA, 2012, p. 3). Ao descrever as duas primeiras décadas do século $\mathrm{XX}$ na Região de Colonização Italiana do Nordeste do Rio Grande do Sul (RCl), o autor expõe que não existem registros de turismo na região, apenas de lazer, sendo o filó um desses. Ao explicar no que consiste a prática, Valduga (2012, p. 9) salienta: "[...] dizem respeito a encontros nas casas de parentes e amigos em diferentes momentos, como uma visita mais demorada, ou em momentos de doença ou perda de algum parente ou amigo". 
$\mathrm{Na}$ edição de 2015 do seminário, Valduga publica o artigo "Enoturismo no Vale dos Vinhedos/RS: uma análise da oferta e demanda turística" que também possui a autoria de Braulio Oliveira. $\mathrm{Na}$ análise da oferta turística na região, um dos pontos destacados pelos autores são os filós italianos realizados em salões comunitários e abertos ao público. Explicam que esses eventos são "encontros ao redor da mesa com cantorias regionais, festas do vinho e do espumante. Contudo, atualmente, turistas e residentes se encontram nos eventos, não sendo mais restritos às comunidades." (VALDUGA; OLIVEIRA, 2015, s/p). Aqui é possível uma aproximação com os dizeres dos entrevistados na pesquisa de Porto (2015) antes referida.

Fabiana de Lima Sales apresentou, na III edição do Seminário da ANPTUR realizado juntamente ao IV SeminTUR, a pesquisa intitulada "O desenvolvimento econômico de Caxias do Sul 2015) na perspectiva do acervo do Museu Municipal".

No artigo, Sales (2006, p. 10-11) descreve o estabelecimento comercial (bodega) representado no acervo do museu e, a partir disso, práticas sociais realizadas pelos homens na bodega: "Fazia parte da sua cultura o filó, onde se conversava e bebia cachaça, e onde também se concentravam os jogos: jogos de carta, de bocha".

Outro artigo presente nos anais do evento e que aborda o filó - dessa vez na edição de 2009 - é a pesquisa desenvolvida por Possamai, Gastal e Negrine. Esses, também são os autores do único artigo publicado em periódico, no ano de 2010. Ambos os trabalhos apresentam uma pesquisa com idosos na Serra Gaúcha em que o foco é a memória desses em relação às práticas de lazer e viagens na sua juventude. Essa pesquisa foi realizada em 2008, na disciplina Turismo e Cultura do curso de Graduação em Turismo da Universidade de Caxias do Sul. A coleta de dados foi realizada pelos alunos da disciplina, cada qual entrevistando um idoso de suas relações pessoais (total de 19 entrevistados).

Sobre as viagens, um dos entrevistados destacou que eram feitas, dentre outros motivos, para ir aos filós, os quais foram citados quatro vezes como forma de lazer, sendo sábado o dia da realização da prática. A partir desses resultados, os autores apresentam as seguintes informações sobre os encontros:

Os filós eram outra forma de lazer, geralmente ocorriam na casa de alguém. Nos filós as mulheres faziam "dressa" e crochê e os homens jogavam baralho. (POSSAMAI; GASTAL; NEGRINE, 2009, s/p, grifo dos autores).

Filós eram encontros comuns entre os italianos da zona rural. Várias famílias se reuniam, à noite, para conversar, jogar, ou realizar trabalhos manuais. (GASTAL; POSSAMAI; NEGRINE, 2010, p. 99).

O lazer feminino estava associado aos bailes, ao assistir jogos de futebol, para torcer pelos homens da família e aos filós. Os filós ocorriam com frequência, geralmente na casa de alguém da vizinhança, onde as mulheres faziam trabalhos manuais e os homens jogavam cartas. Percebe-se pelos depoimentos a importância dada a integração durante as atividades de lazer, pois mesmo que as distâncias fossem difíceis de serem vencidas, as pessoas buscavam formas de participar. (GASTAL; POSSAMAI; NEGRINE, 2010, p.107).

Em 2016, no Seminário ANPTUR, Camilotto e Santos (2016, s/p) publicaram o artigo "As relações de hospitalidade na memória sobre os filós em uma região de colonização italiana no Rio Grande do Sul", no qual as autoras buscam "analisar a prática sociocultural do filó domiciliar do ponto de vista das relações de hospitalidade, com base em narrativas de descendentes de imigrantes italianos obtidas em entrevistas" realizadas por dois projetos de pesquisa: um, em 2005, produzido pelo Instituto Memória Histórica e Cultural (vinculado à Universidade de Caxias do Sul - UCS), com comunidades próximas ao Rio das Antas, na Serra Gaúcha; o outro, elaborado para um trabalho de conclusão de curso em 2015, com moradores de Arvorezinha, município localizado no Vale do Taquari. A partir dos relatos, as autoras analisam que:

Fica marcada a experiência coletiva permeada por cooperação e solidariedade. A importância dos momentos vividos no filó residia no encontro de compartilhamento, de 
fortalecimento dos laços sociais. Dessa forma, instituía-se o sentimento de comunidade cujos elos se construíam nas afinidades. Não se perdia a individualidade, mas se construía, reconstruía e ressignificava uma identidade, um sentimento de pertencimento, de celebração de um vínculo comum. [...] No filó, todos se tornavam acolhidos e acolhedores alternadamente, pois demandas descentradas e a prevalência de um status de igualdade quanto a demandas e condições de troca, desencadeavam e mantinham uma simetria relacional, oportunizando a geração de saberes, de transformações cognitivas, afetivas e relacionais. Cada indivíduo olhava para o outro, buscando olhar com o olhar do outro, fortalecendo assim a efetivação de uma sociodinâmica de acolhimento em que estavam impressas marcas de identificações empáticas, colaborativas (CAMILOTTO; SANTOS, 2016, s/p).

A descrição aqui efetivada da busca em artigos, dissertações, teses e em anais de eventos, certifica que apenas um estudo tem como foco principal o filó, sendo que os demais aludem à prática no decorrer do trabalho como informação ou resultado adicional às pesquisas realizadas. Também foi possível identificar a existência de pesquisas que abordam o filó como um possível atrativo turístico (NARDIN, 2015; PORTO, 2015; VALDUGA; OLIVEIRA, 2015). Somente um trabalho analisa essa prática tendo o viés da hospitalidade, enquanto os demais apenas referem relações que possibilitam essa leitura.

\section{Considerações finais}

Como os estudos dão a conhecer, nos filós, as pessoas conversavam sobre seus cotidianos, comiam e bebiam o que, fruto do trabalho na roça, era fornecido pelo solo, exprimiam sua fé na religião através da reza, praticavam jogos, faziam artesanato para decoração das casas e vestimentas, ou então confeccionavam ferramentas para o trabalho no campo; e também cantavam sobre suas dores e sobre suas esperanças. Como resultado, relações de hospitalidade/acolhimento concretizavam-no como encontro de comunhão, celebração e trocas.

Dados empíricos e pesquisas revelam a manutenção, em determinadas localidades do país (neste trabalho, circunscritas ao Rio Grande do Sul), dessa prática herdada dos antepassados imigrantes italianos. Que outras configurações assumem, para além das interações sociais, as relações de hospitalidade/acolhimento na ótica da constituição e/ou fortalecimento de laços sociais que aí se verificam? Essa é uma questão cujo estudo se reveste de relevância, pois aí estão em jogo traços de uma dinâmica sociocultural que se mantém e se reatualiza. Eis onde se situa esta revisão inicial de literatura na direção de identificar, analisar e interpretar produções acadêmicas, no âmbito de teses, dissertações, artigos publicados em periódicos e em anais de eventos científicos, cujo acesso responde ao termo de busca "filó" ou a este adjetivado por "italiano", conforme considerações anteriores.

Como visto, não se pode considerar que inexistem pesquisas que, direta ou indiretamente, abordem e/ou caracterizem interações efetivadas antes, durante e depois da realização do encontro. Trata-se, contudo, majoritariamente de abordagens não específicas e explicitamente pautadas por teorias de hospitalidade, ou nas quais o filó não se constitui em foco central dos estudos. Essa lacuna vem contribuir para justificar a proposição em desenvolver investigações que tenham em vista depreender relações de hospitalidade em filós na forma como atualmente se realizam. Eis onde se situa esta revisão inicial de literatura da qual o presente trabalho se constitui em uma síntese. Contudo, no sentido de aprofundar análises que se mostram ainda pertinentes para a construção de um referencial teórico com a consistência científica sempre almejada, a revisão poderá/deverá ter prosseguimento mediante algumas incursões em produções de autores clássicos no campo da imigração italiana no Rio Grande do Sul, de sorte a construir uma contextualização histórico-social mais ampla dessa prática e nela melhor poder situar, caracterizar e analisar aquelas que ainda ocorrem nos dias atuais, perspectivando relações de hospitalidade/acolhimento entre aqueles que dela participam. 


\section{Referências}

$8^{\circ}$

SEMINTUR. Disponível em: <https://www.ucs.br/site/eventos/8-semintur/>. Acesso em: 15 out. 2016.

CAMILOTTO, S.; SANTOS, M. M. C. dos. As relações de hospitalidade na memória sobre os filós em uma região de colonização italiana no Rio Grande do

Sul. In: SEMINÁRIO DA ASSOCIAÇÃO NACIONAL DE PESQUISA E PÓS-GRADUAÇÃO EM TURISMO, 13., 2016, São Paulo. Anais... São Paulo: Associação Nacional de Pesquisa e Pós-Graduação em Turismo, 2016. Disponível em:

$<$ http://www.anptur.org.br/anptur/anais/v.12/DH T2/553.pdf >. Acesso em: 12 abr. 2017.

DA CÁS, L. E. Aspecto Lírico-Religioso das Canções Marianas: Um estudo sobre as metáforas e metonímias que representam Maria. 2009. 159 f. Dissertação (Mestrado em Letras, Cultura e Regionalidade) -Universidade de Caxias do Sul, Caxias do Sul, 2009. Disponível em: $<$ https://repositorio.ucs.br/xmlui/handle/11338/4 15>. Acesso em: 01 ago. 2016.

FILIPPON, M. I. A casa do imigrante italiano, a linguagem do espaço de habitar. 2007. $153 \mathrm{f}$. Dissertação (Mestrado em Letras e Cultura Regional) -Universidade de Caxias do Sul, Caxias do Sul, 2007. Disponível em: $<$ https://repositorio.ucs.br/xmlui/handle/11338/2 41>. Acesso em: 01 ago. 2016.

GASTAL, S. de A.; POSSAMAI, A. M. de P.; NEGRINE, A. da S. A Viagem e a Memória do Idoso: um estudo na região da Serra Gaúcha. Turismo em Análise, São Paulo, v. 21, n. 1, p. 89-109, abr. 2010. Disponível em: <http://www.revistas.usp.br/rta/article/view/142 07>. Acesso em: 12 ago. 2016.

GOMES, V. F. Os filós comunitários e a cultura italiana. 2008. Monografia (Licenciatura em História) -Centro Universitário UNIVATES, Lajeado, 2008. Disponível em: $<$ https://www.univates.br/bdu/bitstream/10737/ 569/4/2008VanderlisaFerreiraGomes.pdf>. Acesso em: 15 abr. 2015.

GOMES, V. F.; LAROQUE, L. F. da S. História e cultura dos italianos e seus descendentes: 0 costume do filó em localidades do Vale do Taquari/RS. Revista Destaques Acadêmicos, Lajeado, ano 2, n. 2, p. 33-43, 2010. Disponível em:

<http://www.univates.br/revistas/index.php/dest aques/article/view/217>. Acesso em: 03 mar. 2015.

KÖCHE, J. C. Fundamentos de metodologia científica: teoria da ciência e iniciação à pesquisa. 20. ed. atual. Petrópolis, RJ: Vozes, 2002.

MACIEL, M. B. A pátria sem fronteiras: imigração italiana na ficção de Fidélis Dalcin Barbosa. 2007. 125 f. Dissertação (Mestrado em Letras e Cultura Regional) -Universidade de Caxias do Sul, Caxias do Sul, 2007. Disponível em: <https://repositorio.ucs.br/xmlui/handle/11338/2 61>. Acesso em: 01 ago. 2016.

MANFROI, O. A colonização italiana no Rio Grande do Sul: implicações econômicas, políticas e culturais. Porto Alegre: Grafosul, 1975.

NARDIN, C. R. Gostos, Aromas e Sabores: Memórias e Turismo Gastronômico em Bento Gonçalves. 2015. 79 f. Dissertação (Mestrado em História) -Universidade de Caxias do Sul, Caxias do Sul, 2015. Disponível em: <https://repositorio.ucs.br/xmlui/handle/11338/1 101>. Acesso em: 01 ago. 2016.

PERAZZOLO, O. A.; FERREIRA, L. T.; SANTOS, M. M. C. dos; ZERGER, E. Relações de Hospitalidade no Entrecruzamento das Dimensões 'Sincronia' e 'Simetria' no Contexto do Turismo. Revista Rosa dos Ventos Turismo e Hospitalidade, Caxias do Sul, v. 8, n. 4, p. 538-554, out./dez. 2016. Disponível em: <http://www.ucs.br/etc/revistas/index.php/rosad osventos/article/view/4633/pdf>. Acesso em: 12 abr. 2017.

PORTO, P. P. O cancioneiro popular da imigração italiana: a leitura como processo de construção de sentidos na performance da canção. 2015. $221 \mathrm{f}$. Tese (Doutorado em Letras) Universidade de Caxias do Sul em associação ampla UniRitter, Caxias do Sul, 2015. Disponível em: <https://repositorio.ucs.br/xmlui/handle/11338/1 110>. Acesso em: 01 ago. 2016.

POSSAMAI, A. M. de P.; GASTAL, S.; NEGRINE, A. A Viagem e a Memória do Idoso. In: SEMINÁRIO DA ASSOCIAÇÃO NACIONAL DE PESQUISA E PÓS-GRADUAÇÃO EM TURISMO, 6., 2009, São Paulo. Anais... São Paulo: Associação Nacional de Pesquisa e Pós-Graduação em Turismo, 2009. Disponível em:

<http://www.anptur.org.br/novo_portal/anais_an ptur/anais_2009/DLE3/130-237-1-RV.pdf>. Acesso em: 18 ago. 2016.

RIBEIRO, C. M. P. J. O lugar do Canto. In: RIBEIRO, C. M. P. J.; POZENATO, J. C. (Orgs.). Cultura, imigração e memória: percursos e horizontes 25 anos do Ecirs. Caxias do Sul: Educs, 2004, p. 339-345.

SALES, F. de L. O desenvolvimento econômico de Caxias do Sul na perspectiva do acervo do Museu Municipal. In: SEMINÁRIO DA ASSOCIAÇÃO NACIONAL DE PESQUISA E 
PÓS-GRADUAÇÃO EM TURISMO, 3., 2006, Caxias do Sul. Anais... Caxias do Sul: Associação Nacional de Pesquisa e PósGraduação em Turismo, 2006. Disponível em: <http://www.anptur.org.br/novo_portal/portal_a npur/index.php?get_menu_portal_id=7>. Acesso em: 18 ago. 2016.

THOEN, C. F. C. Representações sobre Etnicidade e Cultura Escolar nas Antigas Colônias de Imigração Italiana do Nordeste do Rio Grande do Sul (1905 - 1950). 2011. 154 f. Dissertação (Mestrado em Educação) -Universidade de Caxias do Sul, Caxias do Sul, 2011. Disponível em:

<https://repositorio.ucs.br/xmlui/handle/11338/5 38>. Acesso em: 01 ago. 2016.

TOSCAN, M. P. O Comportamento Linguístico na Comunidade Bilíngue Ítalo-Brasileira de Nova Pádua/RS: Identidade, Prestígio e Estigma Linguísticos. 2005. $189 \quad$ f. Dissertação (Mestrado em Letras e Cultura Regional) Universidade de Caxias do Sul, Caxias do Sul, $2005 . \quad$ Disponível em: <https://repositorio.ucs.br/xmlui/handle/11338/1 48>. Acesso em: 01 ago. 2016.

TRENTO, A. Do outro lado do Atlântico: um século de imigração italiana no Brasil. São Paulo: Nobel, 1989.

VALDUGA, V. Estado e turismo: a construção do patrimônio do vinho no RS (Brasil) de 1900 a 1930. In: SEMINÁRIO DA ASSOCIAÇÃO NACIONAL DE PESQUISA E PÓSGRADUAÇÃO EM TURISMO, 9., 2012, São Paulo. Anais... São Paulo: Associação Nacional de Pesquisa e Pós-Graduação em Turismo, 2012. Disponível em: <http://www.anptur.org.br/novo_portal/anais_an ptur/anais_2012/admin/arquivo/1.pdf>. Acesso em: 20 ago. 2016.

VALDUGA, V. O Processo de desenvolvimento do enoturismo no Vale dos Vinhedos - RS. In: SEMINÁRIO DA ASSOCIAÇÃO NACIONAL DE PESQUISA E PÓS-GRADUAÇÃO EM TURISMO, 5., 2008, Belo Horizonte. Anais... Belo Horizonte: Associação Nacional de Pesquisa e Pós-Graduação em Turismo, 2008. Disponível em: <http://www.anptur.org.br/novo_portal/anais_an ptur/anais_2008/data/96t.pdf>. Acesso em: 18 ago. 2016.

VALDUGA, V. O Processo de Desenvolvimento do Enoturismo no Vale dos Vinhedos. 2007. $149 \mathrm{f}$. Dissertação (Mestrado em Turismo) Universidade de Caxias do Sul, Caxias do Sul, $2007 . \quad$ Disponível em: <https://repositorio.ucs.br/xmlui/handle/11338/1 93>. Acesso em: 01 ago. 2016.

VALDUGA, V.; OLIVEIRA, B. Enoturismo no Vale dos Vinhedos/RS: uma análise da oferta e da demanda turística. In: SEMINÁRIO DA ASSOCIAÇÃO NACIONAL DE PESQUISA E PÓS-GRADUAÇÃO EM TURISMO, 12., 2015, Natal. Anais... Natal: Associação Nacional de Pesquisa e Pós-Graduação em Turismo, 2015. Disponível em: <http://www.anptur.org.br/anptur/anais/v.11/DC L1_pdf/3.pdf>. Acesso em: 15 ago. 2016.

XIII SEMINÁRIO ANPTUR. Disponível em: $<$ http://www.anptur.org.br/seminario/2016/>. Acesso em: 23 maio 2017. 